\title{
¿U.S. Pacific Coastal Droughts Are Predominantly Driven by Internal Atmospheric Variability $\mathscr{0}$
}

\author{
Seung H. Baek, ${ }^{\mathrm{a}, \mathrm{b}}$ Jason E. Smerdon, ${ }^{\mathrm{a}}$ Benjamin I. Cook, ${ }^{\mathrm{a}, \mathrm{c}}$ AND A. Park Williams ${ }^{\mathrm{a}}$ \\ ${ }^{\mathrm{a}}$ Lamont-Doherty Earth Observatory, Columbia University, Palisades, New York \\ ${ }^{\mathrm{b}}$ Department of Earth and Environmental Sciences, Columbia University, New York, New York \\ ${ }^{\mathrm{c}}$ NASA Goddard Institute for Space Studies, New York, New York
}

(Manuscript received 19 May 2020, in final form 4 December 2020)

\begin{abstract}
Droughts that span the states of Washington, Oregon, and California are rare but devastating due to their large spatial coverage and potential loss of redundancies in water, agricultural, and fire-fighting resources. Such pancoastal droughts [which we define using boreal summer volumetric soil moisture along the U.S. Pacific coast $\left(32^{\circ}-50^{\circ} \mathrm{N}\right.$, $\left.115^{\circ}-127^{\circ} \mathrm{W}\right)$ ] require a more precise understanding of the roles played by the Pacific Ocean and internal atmospheric variability. We employ 16-member ensembles of the Community Atmosphere Model version 5 and Community Climate Model version 3 forced with observed sea surface temperatures (SSTs) from 1856 to 2012 to separate and quantify the influences of the tropical Pacific and internal atmospheric variability on pan-coastal droughts; all other boundary conditions are kept at climatological levels to explicitly isolate for the impacts of SST changes. Internal atmospheric variability is the dominant driver of pan-coastal droughts, accounting for $84 \%$ of their severity, and can reliably generate pan-coastal droughts even when ocean conditions do not favor drought. Cold phases of the Pacific Ocean play a secondary role and contribute, on average, only $16 \%$ to pan-coastal drought severity. Spatiotemporal analyses of precipitation and soil moisture along the U.S. Pacific coast corroborate these findings and identify an antiphased wet-dry dipole pattern induced by the Pacific to play a more secondary role. Our model framework expands on previous observational analyses that point to the spatially uniform forcing of internal atmospheric variability as the more dominant mode of hydroclimate variability along the U.S. Pacific coast. The secondary nature of oceanic forcing suggests limited predictability of pan-continental droughts.
\end{abstract}

KEYWORDS: Drought; Atmosphere-ocean interaction; Hydrology

\section{Introduction}

Regional droughts in the states of Washington, Oregon, and California are common, but droughts that span the three states simultaneously (herein pan-coastal droughts) are relatively rare (Wise 2016; Cook et al. 2018). These events nevertheless carry significant risks because of their large spatial extent, which may reduce water and agricultural redundancies to incur disproportionately high costs (Daniels 2016; Jenkins 2017). For instance, the 2015 pan-coastal drought (Fuchs 2015) forced all three Pacific coastal states to declare drought emergencies by spring of 2015 (Nagourney 2015; Lurie 2015). The dry conditions in 2015 not only contributed to the year becoming the United States' biggest wildfire year since careful records were tracked in terms of total area burned at 10.1 million acres (Dickie 2016), but ultimately cost California and Washington $\$ 2.7$ billion and \$700 million in losses, respectively (Rice 2015; Jenkins 2017). Understanding the causes, dynamics, and potential predictability

๑ Denotes content that is immediately available upon publication as open access.

Supplemental information related to this paper is available at the Journals Online website: https://doi.org/10.1175/JCLI-D-200365.s1.

Corresponding author: Seung H. Baek, sbaek@ldeo.columbia.edu of pan-coastal droughts thus holds important implications for mitigating the impacts of these events.

The rarity of pan-coastal droughts may stem in part from the influences of the El Niño-Southern Oscillation phenomenon (ENSO) and the Pacific decadal oscillation (PDO) on precipitation along the U.S. Pacific coast; ENSO and the PDO are important controls on the meridional position of the subtropical jets and the dominant supply of precipitation found in winter storm tracks. Cold phases of ENSO and the PDO are associated with an atmospheric ridge over the subtropical Pacific that diverts subtropical jets and winter storm tracks northward, which enhance and deplete precipitation totals along the northern or southern Pacific coast, respectively (Sarachik and Cane 2010; Gershunov and Barnett 1998; Piechota and Dracup 1996; McCabe et al. 2004). Conversely, warm phases of ENSO and the PDO create atmospheric lows over the subtropical Pacific that divert the subtropical jets and storm tracks southward and induce the inverse effect (Sarachik and Cane 2010; Trenberth and Guillemot 1996). These shifts in the storm tracks straddle $\sim 40^{\circ}-42^{\circ} \mathrm{N}$ latitude (Wise 2010,2016 ) and collectively establish an antiphased wet-dry dipole pattern in precipitation and soil moisture along the Pacific coast of the United States (Dettinger et al. 1998). Consequently, oceanic forcing by itself would make it unlikely for droughts to simultaneously affect the U.S. Pacific coast, particularly when ENSO and the PDO are in phase and enforce their respective hydroclimatic influences (Gershunov and Barnett 1998).

In addition to the dipole-like hydroclimatic influence of ENSO and the PDO, previous studies have also highlighted the 
dominance of a coherent, uniform mode attributed to stochastic internal atmospheric variability in driving U.S. hydroclimate on both interannual and multidecadal time scales (Cayan and Roads 1984; McCabe and Dettinger 2002; Cook et al. 2018; Williams et al. 2020), demonstrating that internal variability unaided by oceanic forcings can cause droughts of substantial spatial extent, duration, and severity (e.g., Coats et al. 2013, 2015; Stevenson et al. 2015; Baek et al. 2019; Erb et al. 2020). Internal atmospheric variability can even work against oceanic forcings to nullify them (Seager and Hoerling 2014; Baek et al. 2019), casting doubt on whether oceanic influences along the U.S. Pacific coast can overwhelm the potentially obscuring effects of atmospheric variability. Further complicating the dipole paradigm is moisture transport to western North America from atmospheric rivers (Lora et al. 2017; Skinner et al. 2020), the dynamical features of which are not yet fully understood (Gimeno et al. 2014). The on-theground conditions will of course be a combination of oceanic and atmospheric influences; any given pan-coastal drought will therefore be the product of variable influences forced by the Pacific Ocean and another by the atmosphere. Identifying how these two factors contribute to pan-coastal droughts is thus critical to the prediction of these devastating events because the conditions of the Pacific can be seasonally predicted (Barnston et al. 1994, 2012) whereas those of the atmosphere are stochastic in nature and thus yield limited forecasting potential (Colfescu and Schneider 2017).

Cook et al. (2018) investigated the role of oceanic forcing and internal atmospheric variability on pan-coastal droughts along the U.S. Pacific coast over the observational interval, specifically examining the relative influences of the Pacific Ocean and internal variability over the region. The authors established that the leading mode of hydroclimate variability along the U.S. Pacific coast is a spatially uniform mode not well correlated with sea surface temperatures (SSTs) or a known climate oscillation (therefore attributed to internal atmospheric variability). They identified the tropical Pacific-driven dipole mode of hydroclimate variability along the western U.S. coast to be the second and less dominant mode of influence. Although the findings of Cook et al. (2018) are robust over the observational interval, the brevity of this interval limits the sampling of rare pan-coastal droughts. Furthermore, the observational record only chronicles one realization of climate variability, thus making it difficult to characterize internal atmospheric variability and its contribution to pan-coastal droughts.

One method to circumvent the challenges posed by the observational record is to employ ensembles of atmospheric models forced with observed SSTs. Such ensembles not only drastically augment the sampling of rare events (such as pancoastal droughts), but by construction allow the separation of internal atmospheric variability and forcing from oceanic conditions (Hoerling and Kumar 2003; Schubert et al. 2004; Seager et al. 2005; Kushnir et al. 2010; Baek et al. 2019). Ensembles of atmospheric model simulations forced with observed SSTs either globally or over the tropical Pacific in particular have been used previously to examine both persistent (e.g., Seager et al. 2005) and spatially widespread (e.g., Baek et al. 2019) droughts over the United States. We apply this methodological framework herein to examine pan-coastal droughts and their association with the leading modes of variability in precipitation and soil moisture along the U.S. Pacific coast. We expand on the findings of Cook et al. (2018) to explicitly determine the extent to which pan-coastal droughts are driven by the tropical Pacific Ocean and atmospheric variability.

\section{Data and methods}

\section{a. Data}

We employ two 16-member ensembles of the Community Climate Model version 3 (CCM3; Kiehl et al. 1996) forced with two different ocean configurations. The Global Ocean-Global Atmosphere (herein CCM3 GOGA) configuration forces the CCM3 atmospheric global circulation model (AGCM) with historical global SSTs derived from Kaplan et al. (1998) and Hadley Centre Sea Ice and SST [HadISST; Rayner et al. 2003; see Seager et al. (2005) for details]. The Pacific Ocean-Global Atmosphere-Mixed Layer configuration (herein CCM3 POGAML) forces the same AGCM with Kaplan SSTs over the tropical Pacific $\left(20^{\circ} \mathrm{S}-20^{\circ} \mathrm{N}\right)$ but imposes a uniform mixed layer everywhere else. Both 16-member ensembles span 1856-2012 on a $\sim 2.8^{\circ}$ latitude-longitude grid. In addition to these CCM3 experiments, we employ a 16-member ensemble of the Community Atmosphere Model 5 (CAM5; Conley et al. 2012) that is forced by the same prescribed oceanic conditions as the CCM3 GOGA experiment (herein CAM5 GOGA). The CCM3 and CAM5 model experiments explicitly isolate for the impacts of SST changes alone-all other forcings are kept at 1950 climatological levels. The CAM5 ensemble spans 18562016 on a $\sim 2.8^{\circ}$ latitude-longitude grid, from which we use the common 1856-2012 interval for intermodel consistency with the CCM3 experiments.

For each of the three 16-member ensembles, we use monthly precipitation (large-scale and convective precipitation total), boreal summer [June-August (JJA)] averages of volumetric soil moisture at 80-cm depth (linearly interpolated for CAM5), boreal winter [December-February (DJF)] averages of SSTs, and DJF averages of geopotential height at $500 \mathrm{mb}$. We also employ version 4.03 of the Climatic Research Unit Time series (CRU TS; Harris et al. 2020) precipitation data, available monthly from $1901-2018$ on a $0.5^{\circ}$ latitude-longitude grid. All fields are linearly detrended to more specifically focus on higher-frequency variability and, in advance of our correlation analyses, to avoid artificially enhancing these estimates due to co-occurring trends that may not be causally related. We convert volumetric soil moisture and geopotential height to standardized anomalies $(\sigma)$ at each grid point relative to the 1856-2012 baseline. SST anomalies are calculated by subtracting 1856-2012 means.

\section{b. Pan-coastal drought identification}

We employ a parallel definition of pan-coastal droughts used in Cook et al. (2018), examining a region that approximates the U.S. Pacific coast $\left(32^{\circ}-50^{\circ} \mathrm{N}, 115^{\circ}-127^{\circ} \mathrm{W}\right)$ and dividing this area into northern and southern regions split at $40^{\circ}$ latitude. We define pan-coastal drought years as those in which (i) the 
JJA volumetric soil moisture over $70 \%$ of the entire coastal region is below $-0.5 \sigma$; and (ii) the area-average soil moisture is below $-0.5 \sigma$ in both the northern and southern regions. This definition was adopted to select for the most extensive and intensive of coastal droughts (Cook et al. 2018).

\section{c. Parsing atmospheric and oceanic contributions}

The 16-member ensembles allow conditions due to atmospheric variability and oceanic forcing to be separated. Consistent with previous studies (e.g., Seager et al. 2005; Kushnir et al. 2010; Baek et al. 2019), we interpret variations in each SST-forced 16member ensemble mean to be due to oceanic forcing. We attribute each ensemble member's deviation from the ensemble mean to internal atmospheric variability. Although residual atmospheric variability may be present in the ensemble mean, its effect is negligible if the ensemble is large enough; a 16-member ensemble has been demonstrated to robustly represent the simulated oceanic forcing (Seager et al. 2005; Kushnir et al. 2010; Baek et al. 2019). Using the CCM3 and CAM5 GOGA ensembles, we separate pan-coastal droughts in the model simulations into contributions from internal atmospheric variability and the global ocean. Similarly, we separate simulated pan-coastal droughts into contributions from internal atmospheric variability and the tropical Pacific Ocean in the CCM3 POGA-ML ensemble. We quantify these contributions from the atmosphere and ocean into percentages by dividing the soil moisture anomalies attributed to the oceanic or atmospheric variations by the total pan-coastal drought composite soil moisture anomaly; these percentages are calculated specifically over the defined U.S. Pacific coastal region.

\section{d. Assigning significance}

We use a bootstrapping technique to determine the significance $(p<0.10)$ of mean soil moisture, geopotential height, and SST during pan-coastal drought years relative to chance. We randomly select and composite $N$ model years with replacement out of the 2512 possible years $(157$ years $\times 16$ ensemble members), where $N$ equals the number of pan-coastal droughts identified in each respective 16-member ensemble. This process is repeated 1000 times to generate a distribution of composites, from which we identify the 5th- and 95th-percentile thresholds. Significance is only assigned to the soil moisture, geopotential height, and SST fields where the value at a given grid point is either below the 5th-percentile or above the 95th-percentile thresholds.

\section{Results}

\section{a. Model-observation comparisons}

To assess whether the CAM5 and CCM3 SST-forced atmospheric models analyzed herein capture real-world dynamics pertinent to our study of pan-coastal droughts, we first examine how model precipitation and JJA soil moisture conditions compare to observations over the U.S. Pacific coast region. Figure 1 plots the monthly mean precipitation total during the water-year (October to September) for the northern and southern regions of the U.S. Pacific coast for observations and the CAM5 GOGA ensemble during their overlapping
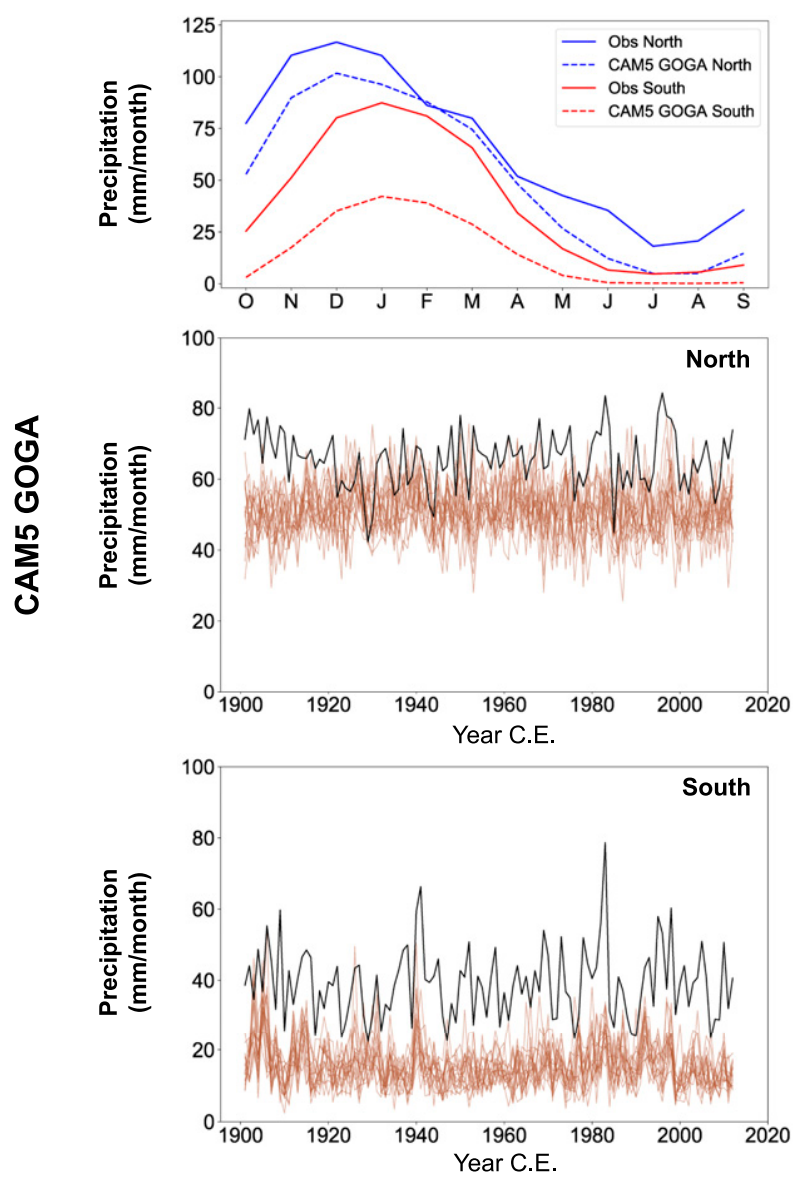

FIG. 1. (top) Monthly mean precipitation climatology during the water year (October-September) for observations and CAM5 GOGA ensemble mean for their overlapping period of 1902-2012 in the northern and southern regions of the U.S. Pacific coast. Time series of average precipitation for the (middle) northern and (bottom) southern regions of the U.S. Pacific coast. Brown lines represent the CAM5 GOGA ensemble members and black line represents observations.

period from 1902 to 2012; time series of precipitation averaged across the northern and southern regions of the Pacific coast are also plotted for observations and the CAM5 GOGA ensemble. Parallel figures for the CCM3 GOGA and POGA-ML ensembles are shown in Figs. S1 and S2 in the online supplemental material, respectively. The models simulate climatological precipitation for the northern region reasonably well relative to observations, but they strongly underestimate longterm mean precipitation totals and interannual variability for the southern region. The models nevertheless capture much of the relative precipitation changes. For instance, in both observations and the model, the northern region experiences more precipitation than the southern region, with much of the precipitation occurring during the cold season (November to April) in both regions; precipitation peaks around December in the northern region and around January in the southern region. 
The systematic dry biases in the SST forced simulations of West Coast precipitation do not negate the usefulness of these models as tools to diagnose SST effects on regional precipitation anomalies of interest. Numerous studies have effectively used the CCM3 and/or CAM5 models to examine North American hydroclimate despite identifying model biases (e.g., Seager et al. 2005; Jong et al. 2018; Bishop et al. 2019). For instance, the CCM3 GOGA and POGA-ML ensembles were cornerstone tools for Seager et al. (2005) in their study of persistent western North American droughts and pluvials, despite some differences relative to observations (e.g., underestimating the length and severity of the Dust Bowl drought). Jong et al. (2018), in their investigation of the failure of the 2015/16 strong El Niño to bring respite to drought in California, also found the CCM3 and CAM5 models to simulate different precipitation responses to similar SST forcings, particularly for Southern California; the CCM3 and CAM5 models were nevertheless useful in identifying a potential for internal atmospheric variability to have nullified the expected above-average precipitation response to the 2015/16 El Niño. These studies demonstrate some of the challenges and limitations associated specifically with the CCM3 and CAM5 models but are also more generally indicative of the biases that exist in all models. In spite of these biases, the CCM3 and CAM5 models have provided dynamical insights not possible with the observational record alone; one simply needs to be cognizant of the limitations and specific caveats they bring. In that regard, the focus of our study is primarily on relative changes of hydroclimate variability; biases in total precipitation are therefore not relevant to our analyses unless they are characteristic of biases in relative variability.

To further assess whether the models capture real-world dynamics pertinent to our study of pan-coastal droughts, we examine how model precipitation and JJA soil moisture conditions compare to observations. Figure 2 shows correlations between interannual variability of JJA soil moisture and interannual variability of total precipitation for each of the 12 months, plotting Pearson's correlation coefficients between (i) total precipitation for each month of the water year and (ii) JJA volumetric soil moisture concurrent with the same water year across the CAM5 GOGA ensemble. To preserve the influences of internal atmospheric variability, these correlation coefficients have been calculated for each respective ensemble member and then averaged across the ensemble. Consistent with observations (see Fig. 1 of Cook et al. 2018), correlations along the U.S. Pacific coast are strongest in April to June for the northern region and January to March for the southern region, highlighting the importance of antecedent winter/ spring precipitation for JJA soil moisture conditions, particularly for the southern region. Parallel figures for the CCM3 GOGA and POGA-ML ensembles (Figs. S3 and S4, respectively) demonstrate that the spatiotemporal patterns of precipitation and their association with soil moisture are largely consistent across the three ensembles. All three ensembles show consistency with water-year results from the observational record (Cook et al. 2018). Based on these comparisons, and despite underestimating absolute precipitation totals (Fig. 1), we interpret subsequent model results as reasonable (but not perfect) representations of real-world relative conditions over the study region. We nevertheless incorporate multiple assessments throughout our results to assess how the models represent the pan-coastal hydroclimate features of interest.

\section{b. Separation of atmospheric and oceanic influences}

Composites of pan-coastal droughts and their associated DJF SSTs and 500-hPa height anomalies for the three ensembles are shown in Fig. 3. The CAM5 GOGA, CCM3 GOGA, and CCM3 POGA-ML ensembles generate 96, 41, and 47 pancoastal droughts, respectively, during 1857-2012 (each ensemble has 16 chances to generate a pan-coastal drought in each year given the 16-member ensemble size). The CAM5 GOGA ensemble generates a larger number of pan-coastal droughts than the CCM3 GOGA ensemble, which we explore further in section 4 . The spatial features of the pan-coastal drought composites, oceanic contributions, and atmospheric contributions simulated by CAM5 GOGA and CCM3 GOGA are nevertheless similar. For example, all three composites show pan-coastal droughts that are driest near the U.S. Pacific coast and taper off toward the east, broadly consistent with the composites of observed pan-coastal droughts in Cook et al. (2018). All three composites furthermore show an atmospheric ridge centered over the U.S. Pacific coast that diverts storm tracks northward and creates wet conditions over Alaska and northern Canada.

We explicitly parse these pan-coastal drought composites into contributions from the ocean (global ocean for the two GOGA ensembles and tropical Pacific for the POGA-ML ensemble) and internal atmospheric variability (Fig. 3). Although we interpret the ensemble mean to be the oceanic forcing and attribute all deviations from the mean to stochastic internal atmospheric variability, in reality stochastic internal atmospheric variability as defined in our study may not truly be random and/or exclusively atmospheric in nature. For instance, any land surface feedbacks and quasi-cyclic oscillatory behavior in precipitation not obviously tied to an oceanic controlling mechanism (see Johnstone 2011; Seager et al. 2015) will be folded into our definition of stochastic atmospheric variability.

Notwithstanding the above caveat, the oceanic contribution manifests as broad but slight drying over the contiguous United States across all three ensembles, with the oceanic contribution from the CCM3 POGA-ML ensemble being the most modest; overall, the SST-forced JJA soil moisture anomaly accounts for $14 \%-18 \%$ of the total anomaly identified during pan-coastal droughts (Fig. 3). The contributions from internal atmospheric variability to pan-coastal droughts are substantially larger across the three ensembles (accounting for $82 \%-86 \%$ of the severity of pan-coastal droughts) and closely resemble the pancoastal composite, suggesting a primary role for internal atmospheric variability driving pan-coastal droughts. Furthermore, this parsing demonstrates that the atmospheric ridge established during (and mostly likely responsible for) the pan-coastal droughts is derived almost entirely from internal atmospheric variability, with minimal contributions from the ocean; Fig. 4 of Cook et al. (2018) similarly suggests atmospheric ridging to be 

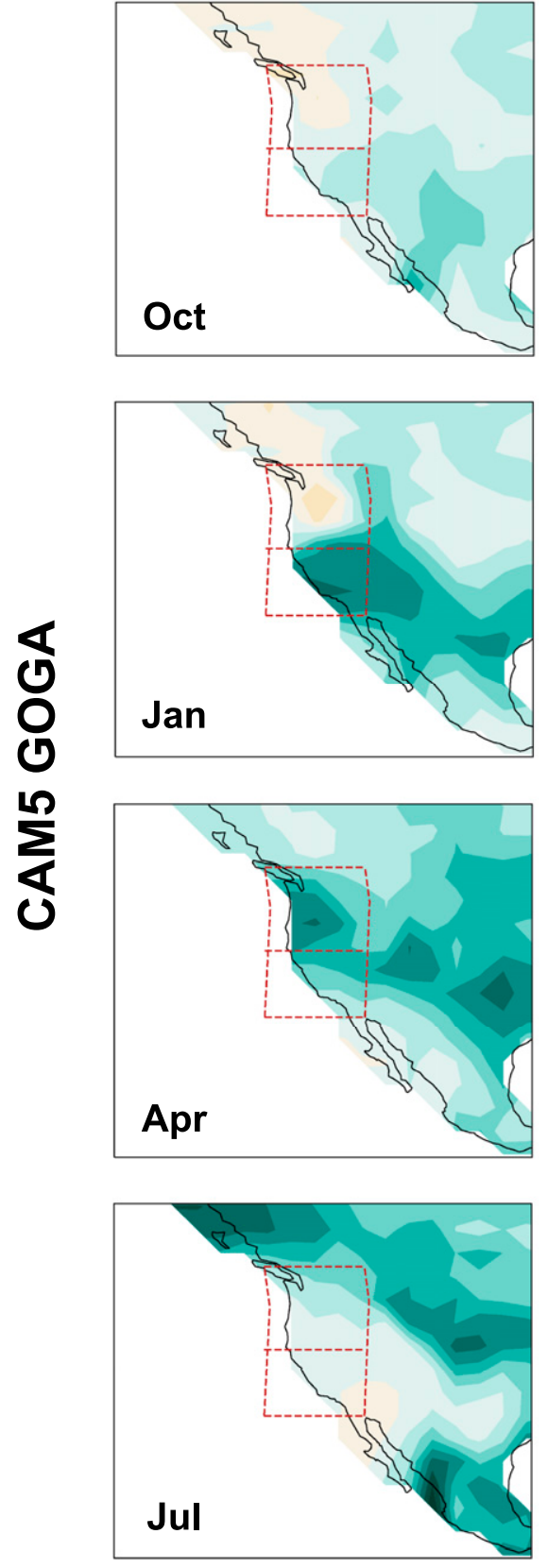
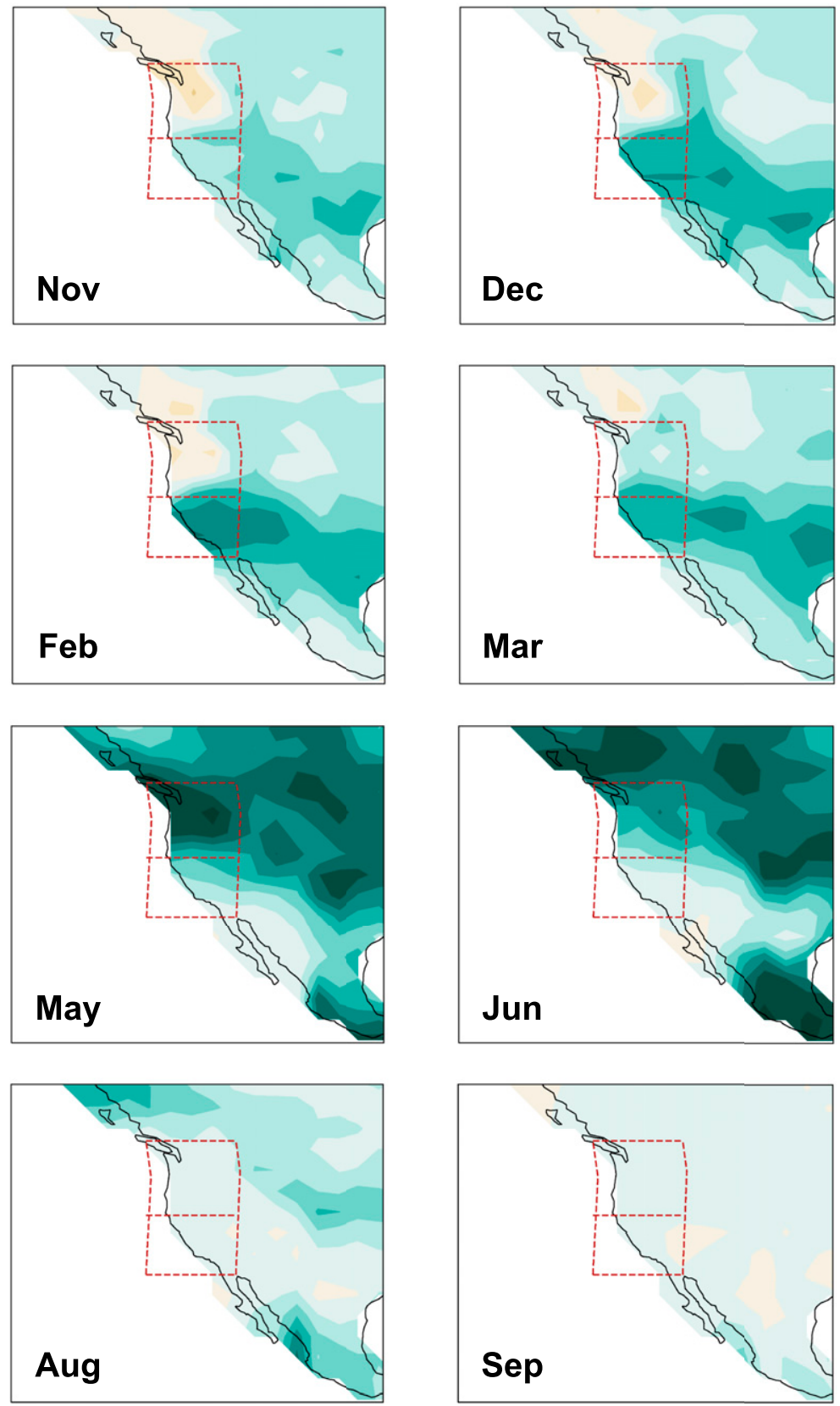

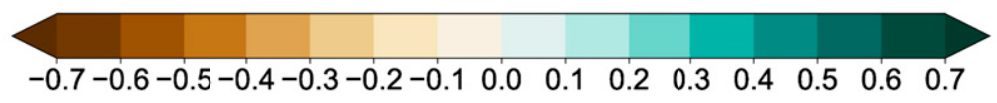

\section{Pearson's Correlation Coefficient $(r)$}

FIG. 2. Point-to-point correlations between precipitation and JJA volumetric soil moisture (concurrent with the same water year) for each month from October to June over 1857-2012 for the CAM5 ensemble. Land regions contained in the boxes indicated with dashed red lines represent the northern and southern domains of the pan-coastal regions considered in this study.

primarily associated with internal atmospheric variability in October-December and January-March. Consistent with the interpretation that atmospheric variability is the dominant influence on pan-coastal droughts, the simulated pan-coastal droughts are spread relatively evenly in time. Pan-coastal droughts occur most often in only one or two members from each 16-member ensemble (Fig. 4). Only seven years across all three ensembles generate pan-coastal droughts in three 


\section{CAM5 GOGA}
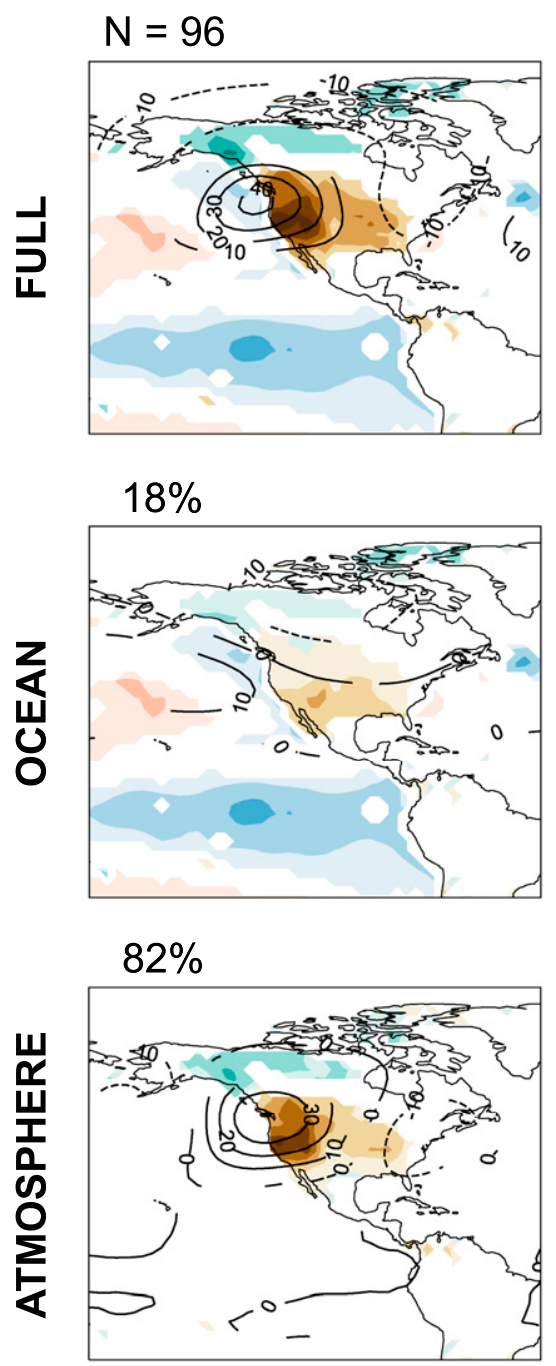

CCM3 GOGA

$\mathrm{N}=41$

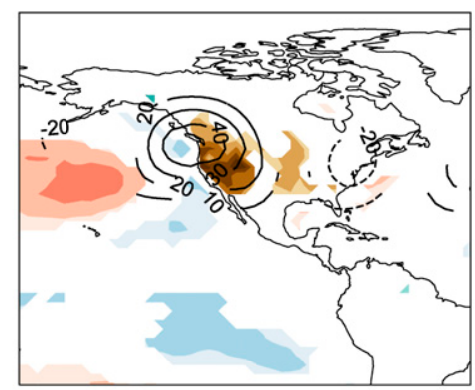

$16 \%$

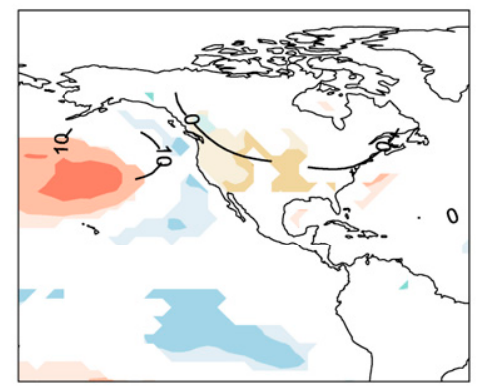

$84 \%$

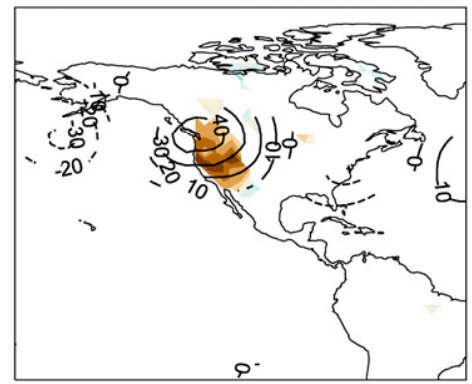

\section{CCM3 POGA-ML}

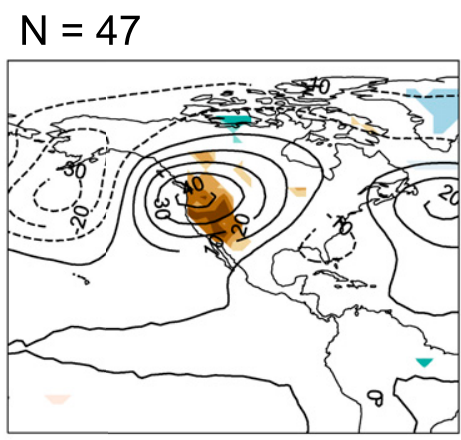

$14 \%$

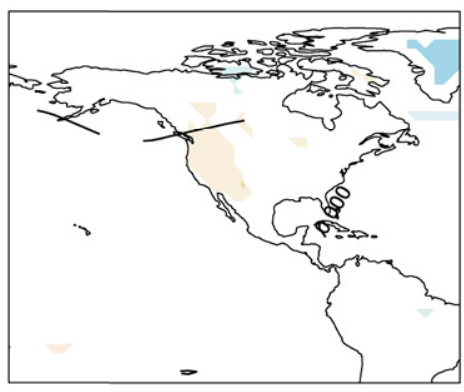

$86 \%$

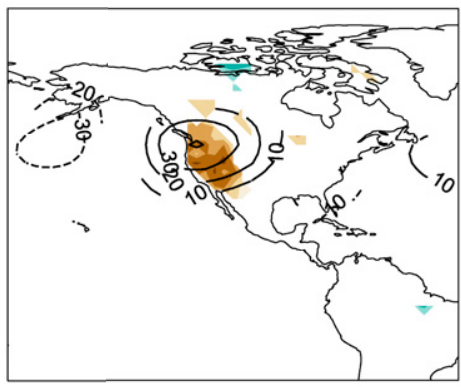

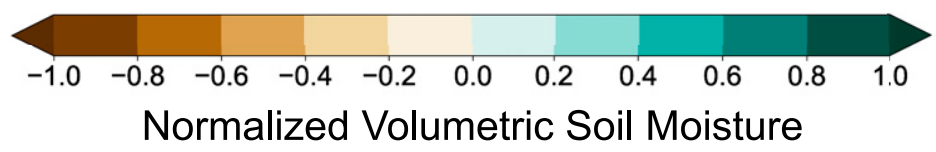

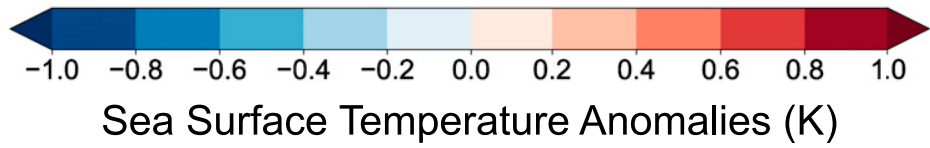

FIG. 3. (top) Composites of pan-coastal droughts defined by JJA soil moisture and their concurrent water year DJF SSTs and 500-hPa height anomalies across the (left) CAM5 GOGA, (middle) CCM3 GOGA, and (right) CCM3 POGA-ML ensembles during 1856-2012. The number of years in the composite is given in the upper-left corner of each panel. (middle) The oceanic contribution to pan-coastal droughts. (bottom) The contribution of internal atmospheric variability to pan-coastal droughts. Only significant values $(p<0.10)$ determined using the bootstrapping technique described in section 2 are plotted. The contribution to the total drought severity from the ocean and atmosphere is given in the upper-left corner in the middle and bottom rows for each model experiment. 


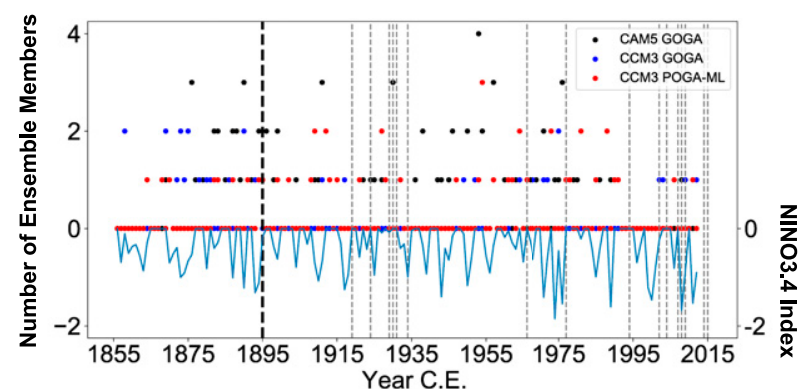

FIG. 4. Time series of the number of ensemble members simulating pan-coastal droughts across the CAM5 GOGA, CCM3 GOGA, and CCM3 POGA-ML ensembles from 1856 to 2012. Vertical gray lines indicate observed pan-coastal droughts identified by Cook et al. (2018), with the black dotted line marking the beginning of the observational interval. Negative values of the DJF Niño-3.4 index are shown in blue (positive values have been replaced with zeros for legibility).

members and only one year (1953 of CAM5 GOGA ensemble) generates pan-coastal droughts in four members. This relatively random distribution of pan-coastal droughts is further evidence that internal atmospheric variability is the dominant cause of pan-coastal droughts, and that oceanic forcing is secondary.

In addition to separating the oceanic and atmospheric contributions, our methodology allows for a comparison of the influence of the tropical Pacific Ocean specifically, relative to the global ocean, on pan-coastal droughts. While SST anomalies in the pan-coastal drought composite of the CAM5 and CCM3 GOGA ensembles show evidence of weak La Niña and cold PDO conditions during pan-coastal drought years (Fig. 3), the CCM3 POGA-ML ensemble displays neutral SSTs over both the tropical Pacific and the North Pacific. The contrasting Pacific conditions during pan-coastal droughts are reflected in the mean DJF Niño-3.4 index values [spatially weighted average DJF SST anomaly (JF for 1856) over the region bounded by $5^{\circ} \mathrm{S}-5^{\circ} \mathrm{N}, 170^{\circ}-120^{\circ} \mathrm{W}$, which are $-0.32,-0.25$, and 0.06 across the CAM5 GOGA, CCM3 GOGA, and CCM3 POGA-ML ensembles, respectively. This suggests that North Pacific SST variability, as measured in observations, is not fully represented in the POGA-ML experiment, which can only generate variability in the North Pacific mixed layer that is forced by the tropical Pacific. Interestingly, the consequence is not only an absence of northern Pacific contributions to pancoastal droughts, but also a negation of the cold tropical Pacific SST anomalies that are evident in the oceanic component of the CCM3 GOGA experiment. A potential implication is that northern Pacific Ocean variability may play a role in the expression of both the tropical and extratropical contributions of the Pacific to pan-coastal droughts. Difference between the magnitude of the northern Pacific contribution in the CCM3 and CAM5 GOGA experiment, however, warrants further investigations into model-dependent representations of northern Pacific influences (comparing the CAM5 and CCM3 GOGA ensembles shows the CCM3 ensemble to exhibit stronger sensitivity to the northern Pacific). In the real world, there is close coupling between the tropical and extratropical Pacific (Amaya 2019; Chiang and Vimont 2004; Larson and Kirtman 2013, 2014). For instance, both the tropical Pacific and extratropical Pacific exert strong controls on Aleutian low variability, and tropical Pacific variability will transfer low-frequency variability to the extratropical Pacific (Vimont 2005; Di Lorenzo et al. 2010, 2015; Newman et al. 2016). In the POGA-ML experiments, tropical Pacific SSTs will thus force some mixed-layer response in the extratropical Pacific, but, in the case of pancoastal droughts, this response does not appear to sufficiently emulate the influence of observed northern Pacific SST variability. The POGA-ML ensemble nevertheless generates a comparable number of pan-coastal droughts with similar spatial characteristics as its GOGA counterpart, indicating that internal atmospheric variability is the main factor driving pancoastal droughts.

To assess the extent to which the Pacific may assist or interfere with internal atmospheric variability in generating pancoastal droughts, we further parse the CAM5 pan-coastal drought composite, ocean contribution, and atmospheric variability contribution into subcomposites during (i) strong El Niños, (ii) weak El Niños, (iii) weak La Niñas, and (iv) strong La Niñas, which we define as when the DJF Niño-3.4 index is (i) more than one standard deviation above the mean, (ii) between half and one standard deviation above the mean, (iii) between half and one standard deviation below the mean, and (iv) more than one standard deviation below the mean, respectively (Fig. 5). We classify all other years as neutral events (i.e., when the DJF Niño-3.4 index is between plus or minus half a standard deviation from the mean). Depending on its state, ENSO can range in its influence from assisting to slightly reducing the forcing of pan-coastal droughts from internal atmospheric variability. A great share of pan-coastal drought years (42 out of 96) occur during La Niñas, when the ocean contributes $23 \%$ to the severity of pan-coastal droughts. The intensity of La Niñas can affect the ocean contribution to pancoastal droughts, but this impact appears modest; for instance, weak and strong La Niñas both contribute $23 \%$ to the severity of pan-coastal droughts. For the most severe La Niñas, when the Niño-3.4 index is greater than 1.5 standard deviations below the mean $(N=9)$, the ocean contributes $27 \%$ (which is only $4 \%$ more than for all other La Niñas). The ocean's contribution is diminished during El Niño states, which comprise a smaller share of pan-coastal droughts (14 out of 96) than La Niñas; neutral events account for the remaining years (40 out of 96). The ocean during weak El Niños contributes $4 \%$ to the severity of pan-coastal droughts. During strong El Niños, the ocean favors wet conditions along the U.S. Pacific coast, and therefore diminishes the severity of pan-coastal drought events. The atmosphere is nevertheless able to drive pan-coastal droughts despite the ocean-forced wet pattern along the U.S. Pacific coast during El Niños, demonstrating that internal atmospheric variability can reliably produce pancoastal droughts even when ocean conditions do not favor them. We also note, however, that the ocean-forced hydroclimatic pattern over North America during pan-coastal droughts during weak El Niños is not canonical. The specific spatial pattern of tropical Pacific SST anomalies in the pan- 


\section{STRONG EL NIÑOS WEAK EL NIÑOS WEAK LA NIÑAS STRONG LA NIÑAS}
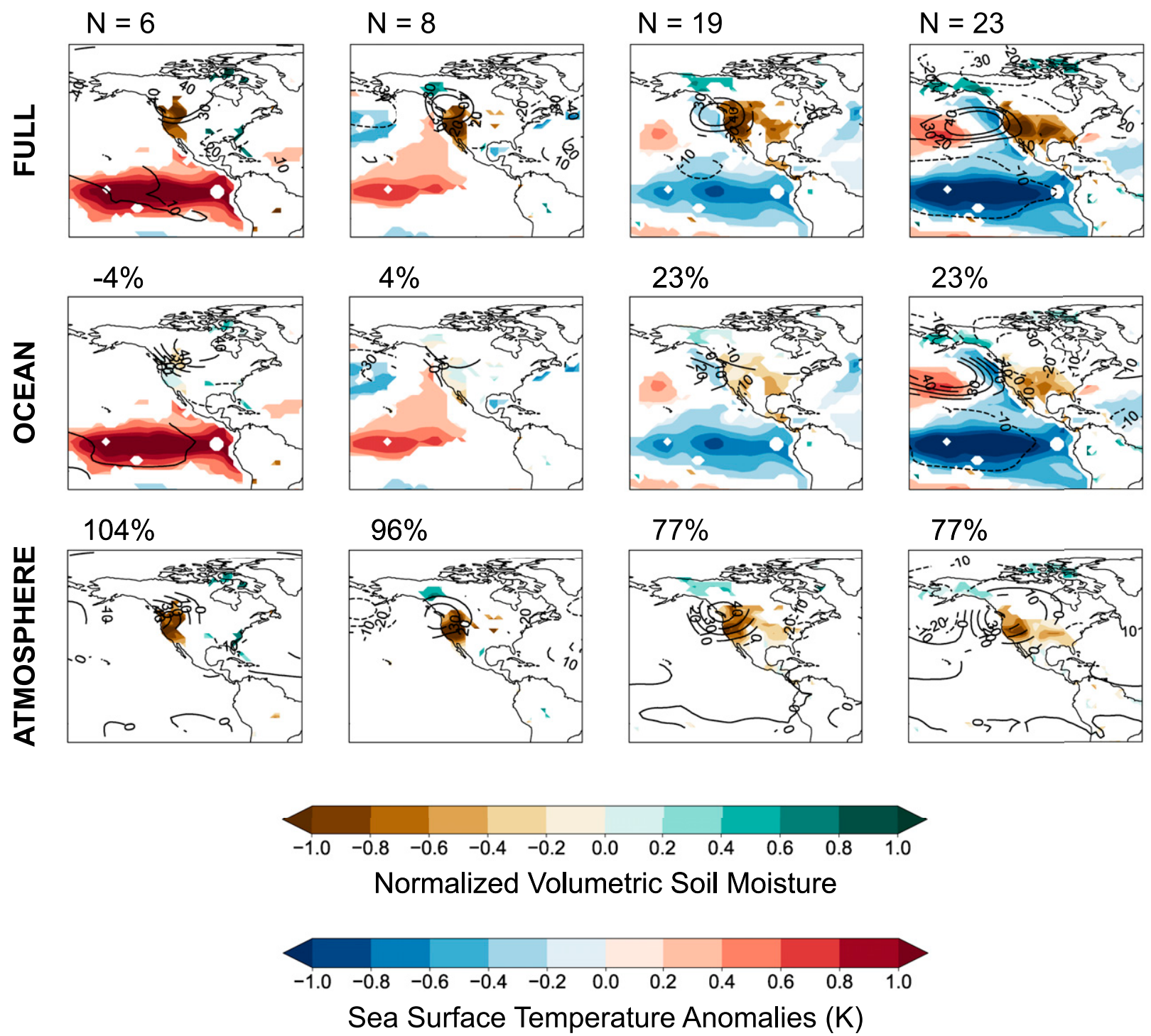

FIG. 5. (top) Composites of pan-coastal droughts defined by JJA soil moisture and their concurrent water year DJF SSTs and 500-hPa height anomalies during (left to right) strong El Niños, weak El Niños, weak La Niñas, and strong La Niñas in the CAM5 GOGA ensemble during 1856-2012. The number of years in the composite is given in the upper-left corner of each panel. (middle) The oceanic contribution to pan-coastal droughts. (bottom) The contribution of internal atmospheric variability to pan-coastal droughts. Only significant values $(p<0.10)$ determined using the bootstrapping technique described in section 2 are plotted. The contribution to the total drought severity from the ocean and atmosphere is given in the upper-left corner in the middle and bottom rows for each model experiment.

coastal drought composite is furthermore more representative of a central Pacific El Niño pattern (Ashok et al. 2007; Freund et al. 2019; Kug et al. 2009), which may play a role in the relative mix of pan-coastal drought forcing from internal atmospheric variability and oceanic contributions during El Niños. While the Pacific's influence is more nuanced than what we explore here, the largest ocean contribution to pan-coastal droughts appears to be during severe La Niñas, which, based on the character of La Niñas sampled over the observational interval, contributes an upper limit of about $27 \%$ to the severity of such events.

\section{c. Identifying the leading drivers of U.S. Pacific hydroclimate variability}

We complement our ability to explicitly separate oceanic and atmospheric influences on pan-coastal droughts with principal component analyses (von Storch and Zwiers 1999) to further investigate the respective influences of oceanic forcing 
CAM5 GOGA
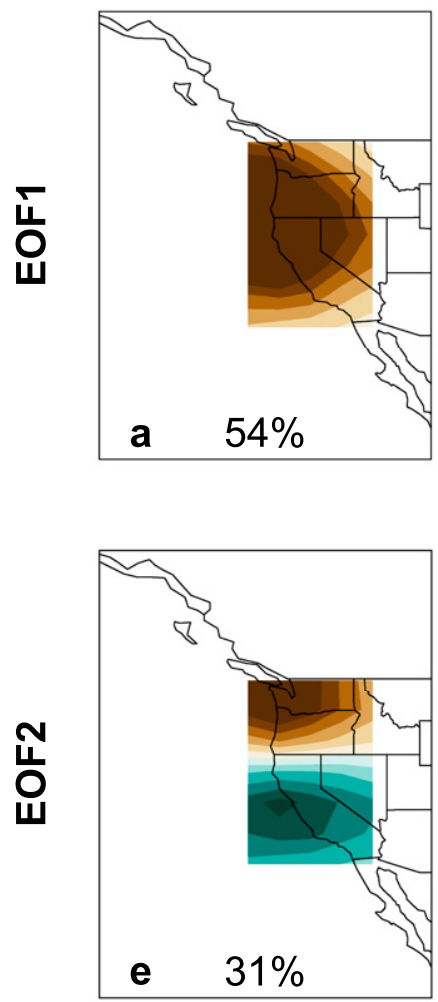

CCM3 GOGA
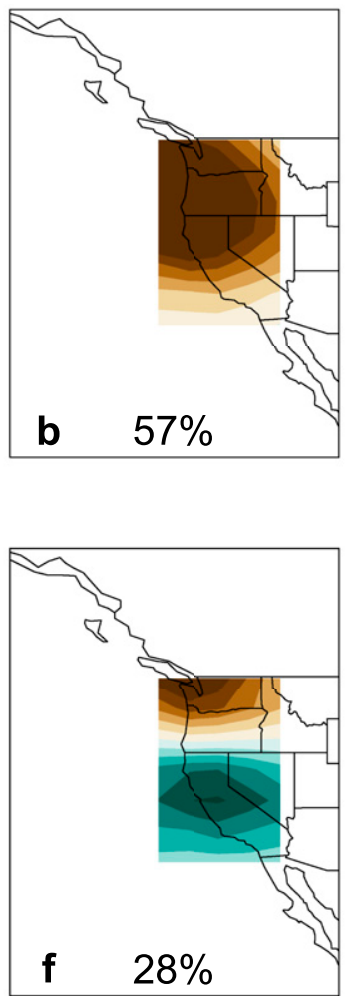

CCM3 POGA-ML
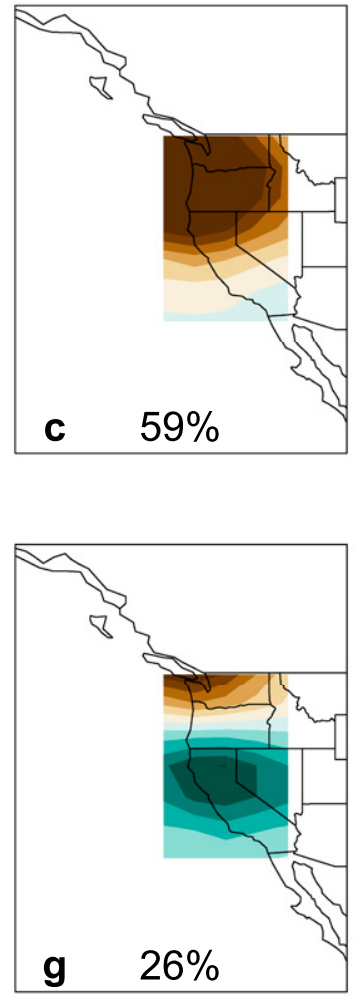

CAM5 Expanded

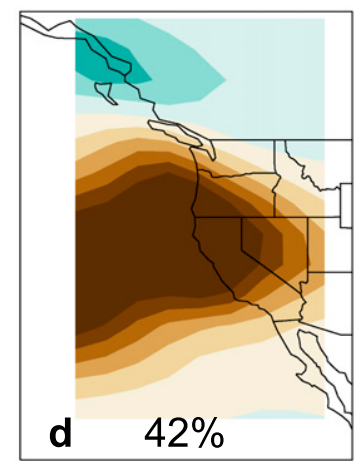

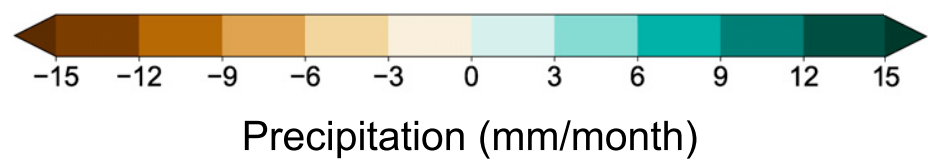

FIG. 6. (top) The first leading EOF of coastal ONDJFM total precipitation for 1856-2012 across the (a) CAM5 GOGA, (b) CCM3 GOGA, and (c) CCM3-POGA-ML ensembles. (d) As in (a), but when the domain is expanded to $21^{\circ}-60^{\circ} \mathrm{N}, 135^{\circ}-112^{\circ} \mathrm{W}$. The number at the bottom represents the percent of the variance explained by each EOF. (bottom) As at top, but for the second leading EOF.

and atmospheric variability on hydroclimate variability along the U.S. Pacific coast; these analyses also parallel those in Cook et al. (2018). Figure 6 shows the first and second empirical orthogonal functions (EOFs) of October to March (ONDJFM) averages of total precipitation variability over 1856-2012 (calculated on a time-concatenated matrix comprising the 16 members of each respective ensemble as opposed to the ensemble mean) along the U.S. Pacific coast across the CAM5 GOGA, CCM3 GOGA, and CCM3 POGA-ML ensembles; the first leading EOF is a spatially uniform pattern explaining $54 \%, 57 \%$, and $59 \%$ of the respective variance, while the second leading EOF is a dipole pattern explaining $31 \%, 28 \%$, and $26 \%$ of the respective variance. These are broadly consistent with the observational findings of Cook et al. (2018), in which the uniform mode was the first leading mode explaining $44 \%-48 \%$ of the variance and appeared largely attributable to internal atmospheric variability; the dipole mode was the second leading mode explaining $24 \%$ of variance and was attributable to oceanic forcing. The precipitation variance attributed to the first and second EOFs for the fully concatenated ensemble is higher in the models than the observations, but the full range of variances explained by the EOFs of each individual ensemble member is more directly comparable to the calculation in the observations. The precipitation variance of the first EOF (second EOF) across the 16-member ensemble ranges from $49 \%$ to $60 \%(26 \%-36 \%), 51 \%$ to $62 \%(24 \%-$ $32 \%)$, and $55 \%$ to $64 \%(23 \%-31 \%)$ for the CAM5, GOGA, and POGA-ML ensembles, respectively, indicating that the leading modes simulated by some ensemble members more closely resemble the observations in terms of variance explained. Regardless of any differences in variances attributed to the two leading modes between models and observations, the relative variance attributed to oceanic forcing with regard to internal atmospheric variability (estimated by dividing the variance explained by the second EOF by that of the first) is $\sim 50 \%$ across the three ensembles and in the observational record.

When the analysis domain is expanded to a greater area of western North America $\left(21^{\circ}-60^{\circ} \mathrm{N}, 135^{\circ}-112^{\circ} \mathrm{W}\right)$, the first EOF 
CAM5 GOGA
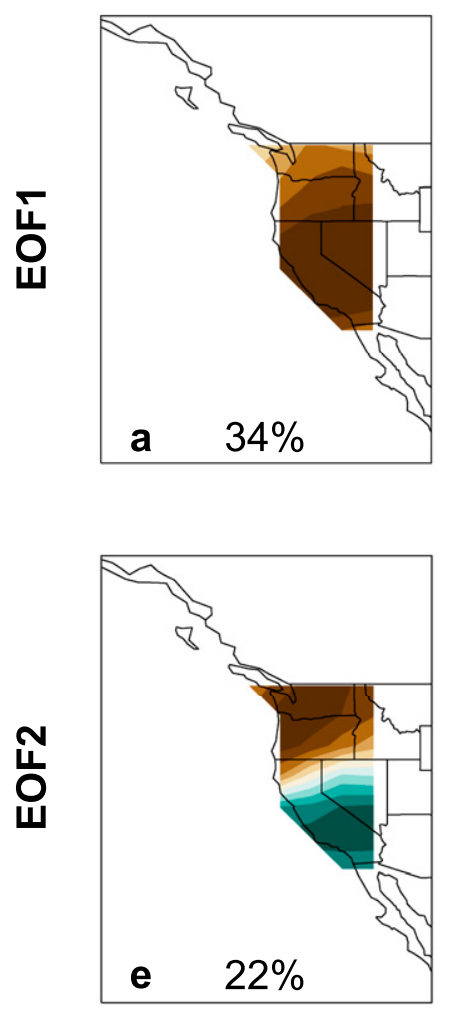

CCM3 GOGA
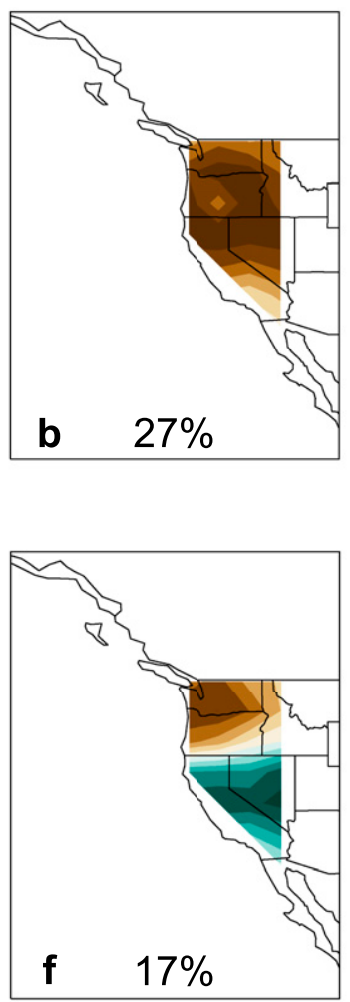

CCM3 POGA-ML
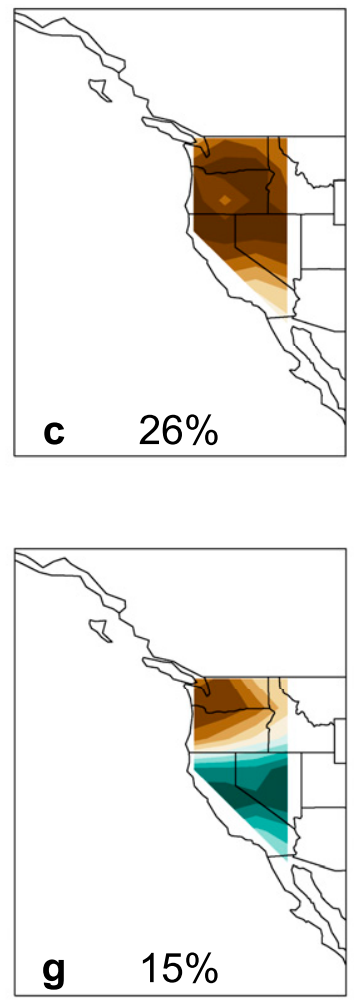

CAM5 Expanded
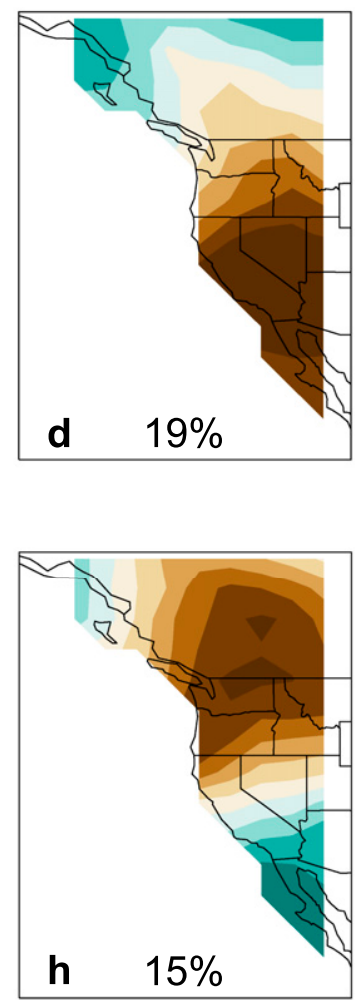

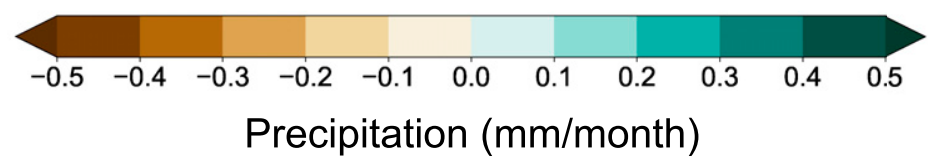

FIG. 7. As in Fig. 6, but for JJA volumetric soil moisture.

of precipitation does resemble a dipole pattern, but the latitude of inflection is much farther north than the $\sim 40^{\circ} \mathrm{N}$ inflection that is attributed to the ENSO dipole forcing (Wise 2010, 2016; Dettinger et al. 1998). These results are also broadly reproduced for JJA soil moisture (Fig. 7); the first EOF resembles a uniform mode accounting for $34 \%, 27 \%$, and $26 \%$ of the variance and the second EOF resembles a dipole mode accounting for $22 \%, 17 \%$, and $15 \%$ of the variance across the CAM5 GOGA, CCM3 GOGA, and CCM3 POGA-ML ensembles, respectively (when calculated on a time-concatenated matrix comprising the 16 members). These results are collectively consistent with those presented by Cook et al. (2018) using only the observational data, even when the EOF results are for the expanded area of western North America, suggesting that the EOF results are robust and not the product of imposed EOF features of orthogonality.

We further explore the association of the first and second leading modes with internal atmospheric variability and oceanic forcing. To do so, we (i) calculate the first principal components (PC1) of ONDJFM precipitation over the pancoastal domain for each of the 16 members of the CAM5 ensemble and (ii) correlate them with their respective ensemble member's concurrent ONDJFM 200-hPa geopotential heights (Fig. 8); only significant coefficients are plotted $(p<$ $0.10)$. In all 16 members, PC1 exhibits correlation coefficients in the northern Pacific that are opposite in sign from coefficients in the tropical Pacific, while consistently exhibiting negative correlations with a homogeneous elliptical feature centered off the U.S. Pacific coast that is characteristic of the atmospheric ridge we have already identified as the feature that dominates the occurrence of pan-coastal droughts. Parallel plots for PC2 (Fig. 9) show more consistently ENSOlike correlation patterns than those represented in Fig. 8, all of which show more widespread and robust coefficients that are symmetric across the equator and are absent the more isolated ridging feature off the U.S. Pacific coast associated with PC1. Although several members of Fig. 8 resemble a pattern that is more characteristic of a symmetric, tropically forced Pacific Ocean mode (e.g., the top-left and bottom-right members), the majority of the ensemble members are characteristic of more randomly distributed patterns that are primarily consistent only through the ridging feature off the U.S. Pacific coast 

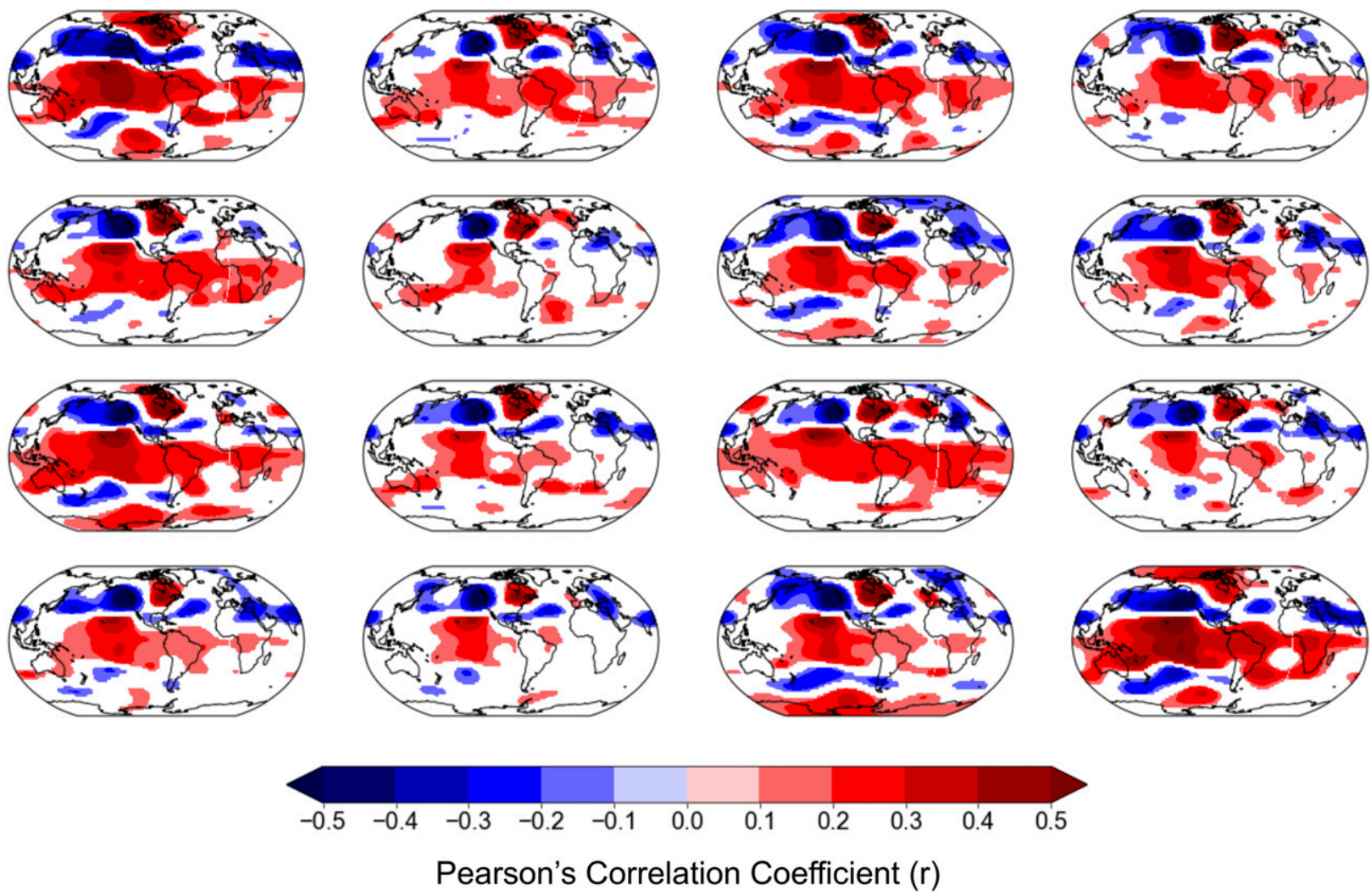

FIG. 8. Point-to-point correlations between PC1, derived from the ONDJFM precipitation field over the pan-coastal domain, and ONDJFM 200-hPa geopotential height for each of the 16 members of the CAM5 ensemble, respectively. Only significant coefficients are plotted $(p<0.10)$.

associated with the uniform precipitation mode. In contrast, every member of Fig. 9 robustly captures a hemispherically symmetric pattern (particularly over the Pacific Ocean basin) that is characteristic of a tropically forced Pacific Ocean mode manifest as a dipole precipitation pattern over the U.S. Pacific coast.

Our interpretations of PC1 and PC2 are further supported in Figs. 10 and 11 that plot Pearson's correlation coefficients $(p<$ $0.10)$ calculated between $\mathrm{PC} 1$ and $\mathrm{PC} 2$ and annual global SSTs for all 16 members of the CAM5 ensemble. While PC1 strongly correlates with ENSO SST patterns in only several of the 16 ensemble members, PC2 correlates with ENSO SST patterns that are consistent across all ensemble members. As in Cook et al. (2018), and in keeping with our analyses that separated the model simulations into internal atmospheric variability and ocean forcing components, our analyses support the physical interpretation that $\mathrm{PC} 1$ represents an internally generated, atmospheric mode largely independent of SSTs and PC2 represents a Pacific-generated dipole mode, despite PC1 and PC2 being statistical constructions.

\section{Discussion and conclusions}

We have examined the representation of pan-coastal droughts in 16-member ensembles of CAM5 and CCM3 atmospheric models forced with observed SSTs. By interpreting the (i) ensemble mean and (ii) deviations from the ensemble mean as forcings from the ocean and internal atmospheric variability, respectively, we have separated contributions to pan-coastal droughts into oceanic and atmospheric components. Our results nevertheless have the following caveats: (i) relative to observations, both the CAM5 and CCM3 models underestimate the climatological total precipitation of the water year along the U.S. Pacific coast, particularly for the southern region and (ii) the CAM5 model simulates more than twice the number of pan-coastal droughts as simulated by the CCM3 model. Despite the model biases, the relative behavior of the simulated hydroclimate and the dynamic interpretations that we derive from the models are consistent with previous observational analyses. Regarding the second caveat, several observations may suggest potential explanations. First, relative to CCM3, the CAM5 GOGA ensemble has a stronger statistically significant connection to ocean forcing over the tropical Pacific (Fig. 3), which is also reflected in the fact that the ocean forcing explains slightly more pan-coastal drought severity $(18 \%)$ than the CCM3 GOGA simulations (16\%). These differences suggest a stronger ENSO teleconnection to the U.S. Pacific coastal region in CAM5 than CCM3, which would translate into more consistent pan-continental droughts 

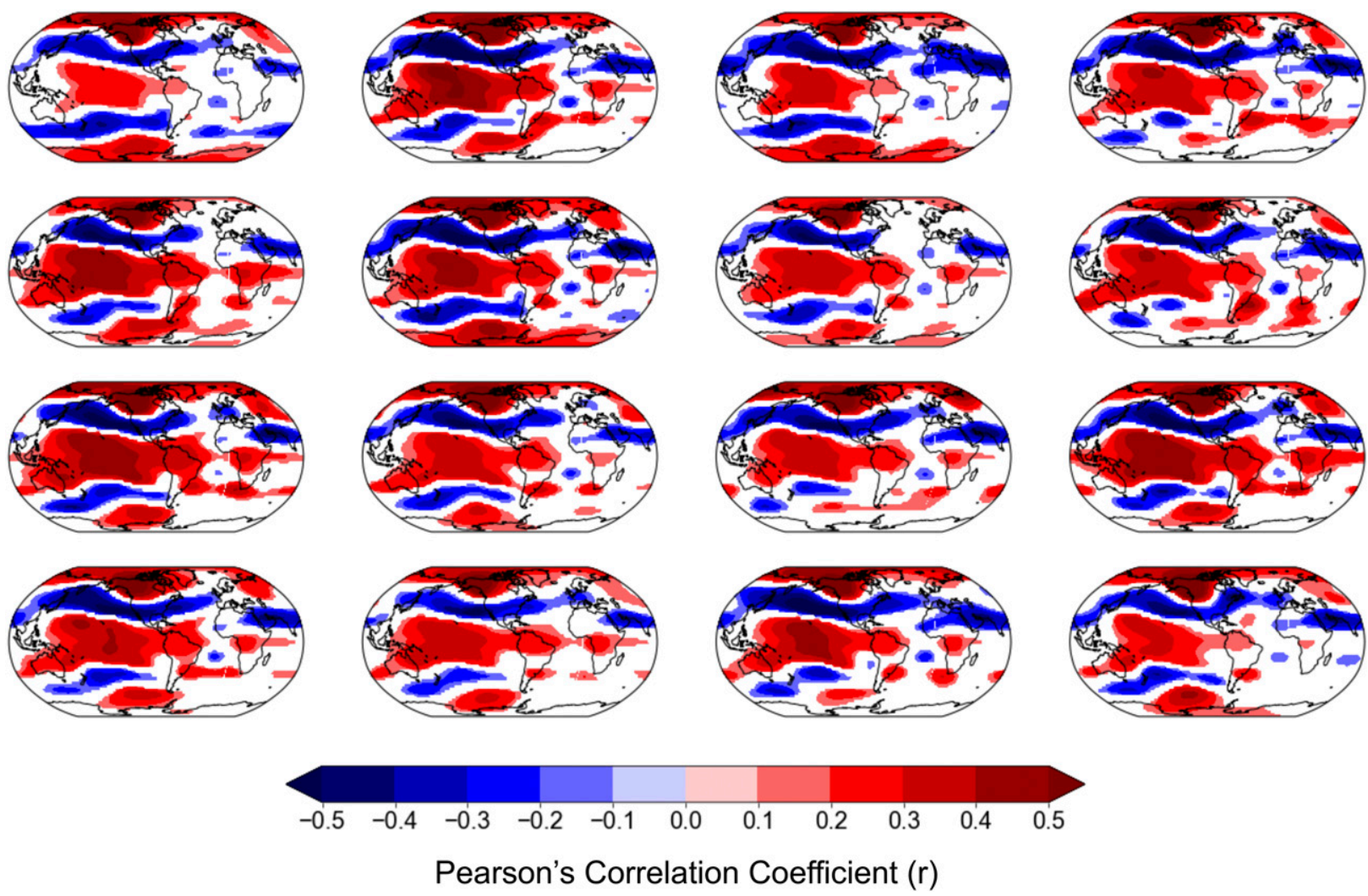

FIG. 9. As in Fig. 8, but for PC2 derived from the ONDJFM precipitation field over the pan-coastal domain.

than would be favored by chance (atmospheric variability) alone. The relative increase in the strength of the oceanic forcing within CAM5 is nevertheless only a small increase over CCM3 and is unlikely to be the only explanation for a number of pan-continental droughts that is more than twice as large in CAM5 than in CCM3. It is therefore also possible that both the strength of the oceanic forcing and the magnitude of internal atmospheric variability are larger in CAM5, yielding only a small change in the relative contributions to pan-continental droughts from the ocean and atmosphere, but a large increase in the overall number of the events. This possibility is underscored in Fig. 4, which shows CAM5 to have the largest occurrence of single years in which multiple ensemble members simulate pan-continental droughts; 1953 includes four ensemble members with pancontinental droughts, while six years include three ensemble members that simulate such droughts. The CCM3 POGA-ML ensemble includes only one year in which three ensemble members simulate a pan-continental drought, otherwise the two CCM3 simulations only include pan-continental drought years shared by two or one ensemble members. Finally, it is also possible that there are other dynamics pertinent to our study of pancoastal hydroclimate variability that are represented differently in the two atmospheric models. All of the above possible explanations should be investigated in future studies given that the incidence of pan-continental droughts is important to accurately quantify, particularly if one is interested in understanding how those numbers may change into the future under a warming climate.

Despite the described caveats, our results show that the atmospheric ridge responsible for pan-coastal droughts is derived mostly from internal atmospheric variability in the SST-forced model simulations. Despite an association with both La Niña and cold PDO conditions, the global ocean plays a secondary role driving pan-coastal droughts, while internal atmospheric variability is the dominant influence on these events. EOF analyses of modeled winter precipitation show a uniform mode, attributable to internal atmospheric variability, and a dipole mode, attributable to Pacific Ocean forcing, to comprise the first and second leading modes of hydroclimate variability along the U.S. Pacific coast, consistent with previous observational analyses (Cook et al. 2018). This contrasts with the paradigm of the Pacific-induced dipole as the leading mode of precipitation variability along the U.S. Pacific coast, which remains attractive in part because the strong teleconnections to the Pacific combined with the predictability of ENSO events would suggest possible forecasting of pan-coastal droughts 6 months or more in advance (Barnston et al. 1994, 2012). The dominance of internal atmospheric variability along the U.S. Pacific coast nevertheless remains well documented and is reinforced by the expanded sampling of internal atmospheric variability provided by our model framework. 

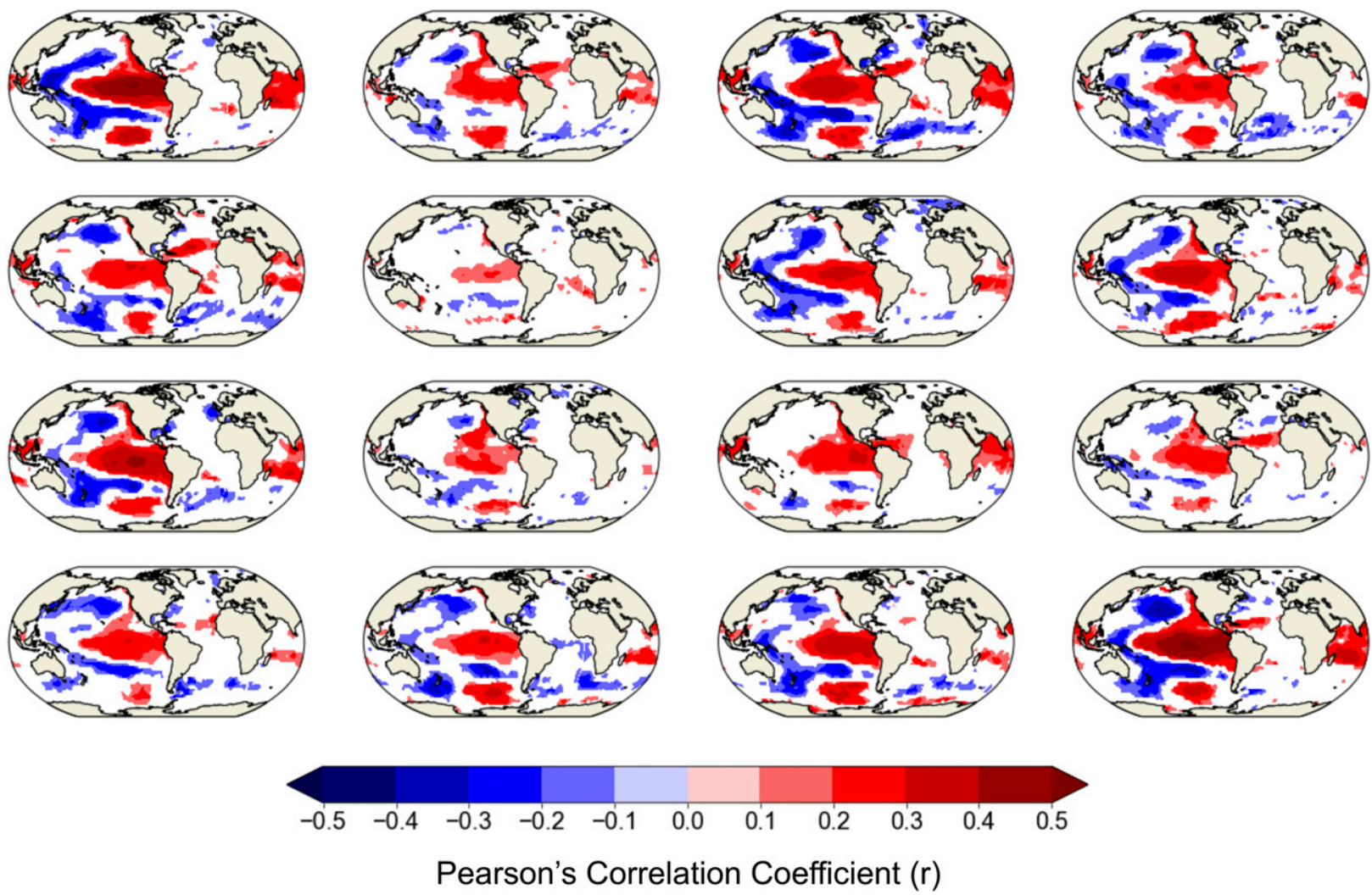

FIG. 10. Point-to-point correlations between PC1, derived from the ONDJFM precipitation field over the pan-coastal domain, and ONDJFM SSTs for each of the 16 members of the CAM5 ensemble, respectively. Only significant coefficients are plotted $(p<0.10)$.

Our model results suggest limited predictability of pan-coastal hydroclimate variability (including pan-coastal droughts) because any secondary oceanic forcings may become lost in the chaos of the atmosphere. The recent failure of the anomalously strong 2015/16 El Niño to bring respite to the 2012-15 California drought further highlights the challenge of using Pacific SSTs as predictors of pan-coastal droughts (Kintisch 2016; Jong et al. 2018). While not fully predictive, La Niñas nevertheless do enhance both the incidence and severity of pan-coastal droughts and can thus still provide useful insight into the likelihood of pan-coastal droughts. The limited predictability of pan-coastal droughts persists despite the strong correlations of ONDJFM precipitation with JJA soil moisture, demonstrated herein using models as well as in observations (e.g., Cook et al. 2018). While cold season precipitation itself may be difficult to forecast (given the influence of internal atmospheric variability), summer pancoastal droughts will nevertheless be directly impacted by precipitation deficits during the preceding ONDJFM period. Additionally, while we attribute any non-oceanic forcing of pan-coastal droughts to stochastic atmospheric variability, our definition of stochastic internal atmospheric variability may not truly be stochastic or atmospheric in nature. Quasicyclic atmospheric activity, such as the quasi-biennial mode in western U.S. precipitation variability (Johnstone 2011;
Dettinger et al. 1998) for instance, suggests that interannual precipitation variability in the pan-coastal region is likely not completely stochastic in nature, although its mechanism is not yet well understood (and not obviously tied to the global ocean); further research into such quasi-cyclicity may offer additional avenues for predictability. Land surface initializations can also affect atmospheric circulation and have demonstrated forecasting impact, albeit very small, of 30- and 45-day leads for precipitation and temperature, respectively, over parts of North America (Koster et al. 2010). Despite these considerations, our study makes clear the limitations of examining pan-coastal droughts through a Pacificinduced dipole paradigm and highlights the need to further consider internal atmospheric variability as the controlling factor in these events.

Acknowledgments. This work was supported in part by NOAA MAPP award NA20OAR4310414 and NSF Grants AGS-1243204, AGS-1805490, and AGS-1703029. A. P. Williams and B. I. Cook are supported by the NASA Modeling, Analysis, and Prediction Program (MAP-16-0081). We acknowledge Naomi Henderson and Dong-Eun Lee for generating the model simulations employed in this study. The CCM3 experiments are publicly available at http://kage.ldeo.columbia.edu: 81/SOURCES/.LDEO/.ClimateGroup/.PROJECTS/.CCM3/. 

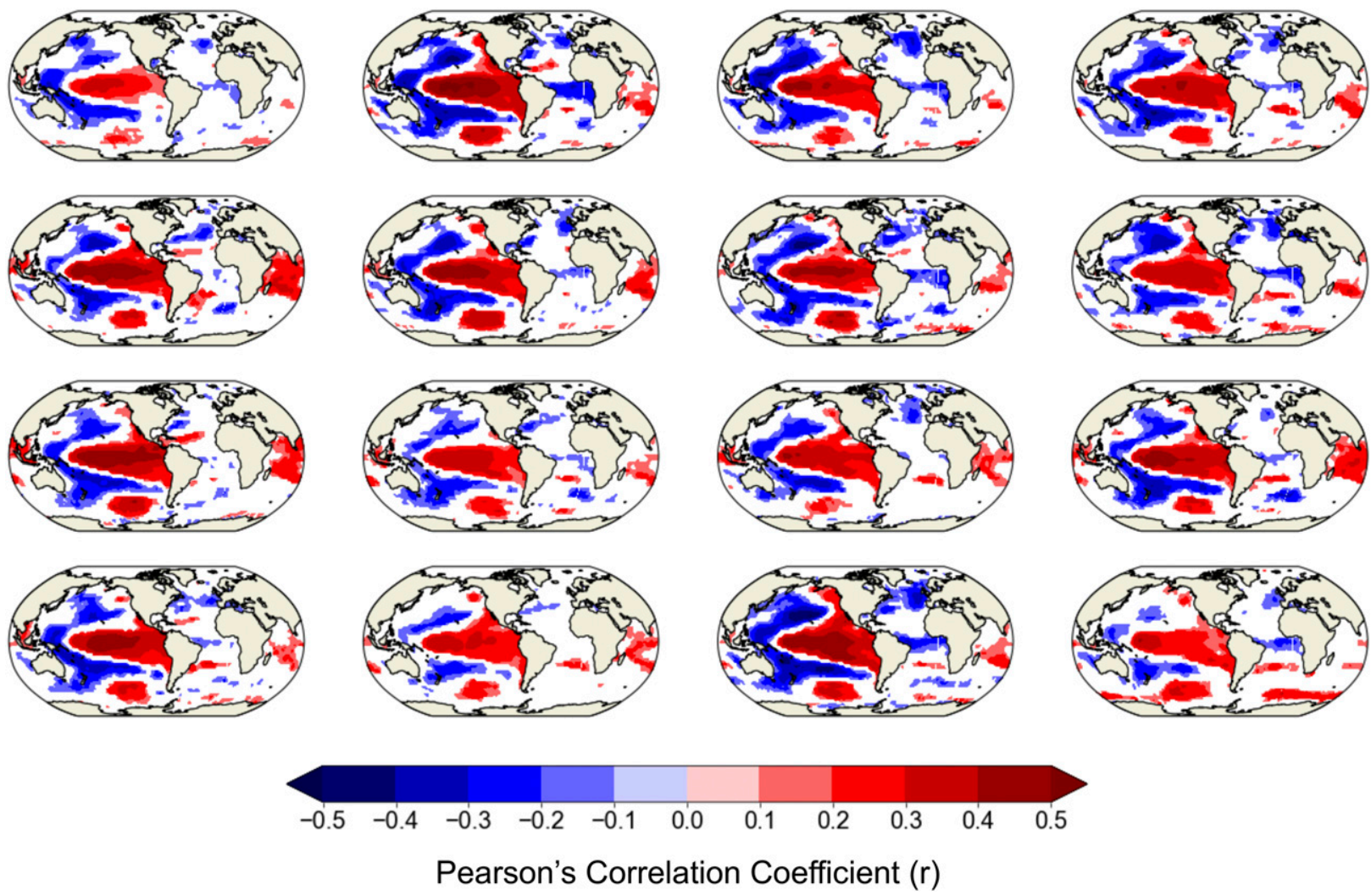

FIG. 11. As in Fig. 10, but for PC2 derived from the ONDJFM precipitation field over the pan-coastal domain.

The CAM5 experiments are publicly available at http://magog. ldeo.columbia.edu:81/home/.dlee/.cam5_goga/. The authors declare no conflicts of interest. This is LDEO contribution number 8374 .

\section{REFERENCES}

Amaya, D. J., 2019: The Pacific meridional mode and ENSO: A review. Curr. Climate Change Rep., 5, 296-307, https://doi.org/ 10.1007/s40641-019-00142-x.

Ashok, K., S. K. Behera, S. A. Rao, H. Weng, and T. Yamagata, 2007: El Niño Modoki and its possible teleconnection. J. Geophys. Res., 112, C11007, https://doi.org/10.1029/2006JC003798.

Baek, S. H., J. E. Smerdon, R. Seager, A. P. Williams, and B. I. Cook, 2019: Pacific Ocean forcing and atmospheric variability are the dominant causes of spatially widespread droughts in the contiguous United States. J. Geophys. Res., 124, 25072524, https://doi.org/10.1029/2018JD029219.

Barnston, A. G., and Coauthors, 1994: Long-lead seasonal forecasts-Where do we stand? Bull. Amer. Meteor. Soc., 75, 2097-2114, https://doi.org/10.1175/1520-0477(1994)075<2097: LLSFDW $>2.0 . \mathrm{CO} ; 2$.

- - M. K. Tippett, M. L. L'Heureux, S. Li, and D. G. DeWitt, 2012: Skill of real-time seasonal ENSO model predictions during 2002-11: Is our capability increasing? Bull. Amer. Meteor. Soc., 93, 631-651, https://doi.org/10.1175/BAMS-D-11-00111.1.

Bishop, D. A., and Coauthors, 2019: Investigating the causes of increased twentieth-century fall precipitation over the southeastern United States. J. Climate, 32, 575-590, https://doi.org/ 10.1175/JCLI-D-18-0244.1.
Cayan, D. R., and J. O. Roads, 1984: Local relationships between United States west coast precipitation and monthly mean circulation parameters. Mon. Wea. Rev., 112, 1276-1282, https:// doi.org/10.1175/1520-0493(1984)112<1276:LRBUSW>2.0. $\mathrm{CO} ; 2$.

Chiang, J., and D. Vimont, 2004: Analogous Pacific and Atlantic meridional modes of tropical atmosphere-ocean variability. J. Climate, 17, 4143-4158, https://doi.org/10.1175/JCLI4953.1.

Coats, S., J. E. Smerdon, R. Seager, B. I. Cook, and J. F. GonzálezRouco, 2013: Megadroughts in southwestern North America in ECHO-G millennial simulations and their comparison to proxy drought reconstructions. J. Climate, 26, 7635-7649, https://doi.org/10.1175/JCLI-D-12-00603.1.

,,-- B. I. Cook, and R. Seager, 2015: Are simulated megadroughts in the North American southwest forced? J. Climate, 28, 124-142, https://doi.org/10.1175/JCLI-D-14-00071.1.

Colfescu, I., and E. K. Schneider, 2017: Internal atmospheric noise characteristics in twentieth century coupled atmosphere-ocean model simulations. Climate Dyn., 49, 2205-2217, https://doi.org/ 10.1007/s00382-016-3440-9.

Conley, A. J., and Coauthors, 2012: Description of the NCAR Community Atmosphere Model (CAM 5.0). NCAR Tech. Note NCAR/TN-486+STR, 289 pp., https://citeseerx.ist.psu. edu/viewdoc/download?doi=10.1.1.422.3202\&rep=rep1\& type $=$ pdf.

Cook, B. I., A. P. Williams, J. S. Mankin, R. Seager, J. E. Smerdon, and D. Singh, 2018: Revisiting the leading drivers of Pacific coastal drought variability in the contiguous United States. J. Climate, 31, 25-43, https://doi.org/10.1175/ JCLI-D-17-0172.1. 
Daniels, J., 2016: California drought costs to top $\$ 600$ million. CNBC, 15 August 2016, http://www.cnbc.com/2016/08/15/californiadrought-costs-to-top-600-million-dollars.html.

Dettinger, M. D., D. R. Cayan, H. F. Diaz, and D. M. Meko, 1998: North-south precipitation patterns in western North America on interannual-to-decadal timescales. J. Climate, 11, 3095-3111, https://doi.org/10.1175/1520-0442(1998)011<3095: NSPPIW $>2.0 . \mathrm{CO} ; 2$.

Dickie, G., 2016: 2015 wildfires burned a record-breaking 10.1 million acres. High Country News, 11 January 2016, https:// www.hcn.org/articles/wildfires-burned-a-record-breaking-101-million-acres-in-2015.

Di Lorenzo, E., and Coauthors, 2010: Central Pacific El Niño and decadal climate change in the North Pacific Ocean. Nat. Geosci., 3, 762-765, https://doi.org/10.1038/ngeo984.

—, G. Liguori, N. Schneider, J. C. Furtado, B. T. Anderson, and M. A. Alexander, 2015: ENSO and meridional modes: A null hypothesis for Pacific climate variability. Geophys. Res. Lett., 42, 9440-9448, https://doi.org/10.1002/2015GL066281.

Erb, M. P., J. Emile-Geay, G. J. Hakim, N. Steiger, and E. J. Steig, 2020: Atmospheric dynamics drive most interannual U.S. droughts over the last millennium. Sci. Adv., 6, eaay7268, https://doi.org/10.1126/sciadv.aay7268.

Freund, M. B., and Coauthors, 2019: Higher frequency of Central Pacific El Niño events in recent decades relative to past centuries. Nat. Geosci., 12, 450-455, https://doi.org/10.1038/s41561-019-0353-3.

Fuchs, B., 2015: U.S. drought monitor, July 7, 2015. National Drought Mitigation Center, University of Nebraska- Lincoln, https://digitalcommons.unl.edu/cgi/viewcontent.cgi? article $=$ $1154 \&$ context $=$ droughtarchive.

Gershunov, A., and T. P. Barnett, 1998: Interdecadal modulation of ENSO teleconnections. Bull. Amer. Meteor. Soc., 79, 27152725, https://doi.org/10.1175/1520-0477(1998)079<2715: IMOET $>2.0 . \mathrm{CO} ; 2$.

Gimeno, L., R. Nieto, M. Vázquez, and D. A. Lavers, 2014: Atmospheric rivers: A mini-review. Front. Earth Sci., 2, 2, https://doi.org/10.3389/feart.2014.00002.

Harris, I., and Coauthors, 2020: Version 4 of the CRU TS monthly high-resolution gridded multivariate climate dataset. Sci. Data, 7, 109, https://doi.org/10.1038/s41597-020-0453-3.

Hoerling, M., and A. Kumar, 2003: The perfect ocean for drought. Science, 299, 691-694, https://doi.org/10.1126/science.1079053.

Jenkins, D., 2017: WSDA estimates '15 drought damage topped $\$ 700$ million. Capital Press, 16 February 2017, http://www. capitalpress.com/Washington/20170216/wsda-estimates-15drought-damage-topped-700-million.

Johnstone, J. A., 2011: A quasi-biennial signal in western US hydroclimate and its global teleconnections. Climate Dyn., 36, 663-680, https://doi.org/10.1007/s00382-010-0755-9.

Jong, B., M. Ting, R. Seager, N. Henderson, and D. E. Lee, 2018: Role of equatorial Pacific SST forecast error in the late winter California precipitation forecast for the 2015/16 El Niño. J. Climate, 31, 839-852, https://doi.org/10.1175/JCLI-D-17-0145.1.

Kaplan, A., M. A. Cane, Y. Kushnir, A. C. Clement, M. B. Blumenthal, and B. Rajagopalan, 1998: Analyses of global sea surface temperature 1856-1991. J. Geophys. Res., 103, $18567-$ 18589, https://doi.org/10.1029/97JC01736.

Kiehl, J. T., J. Hack, G. Bonan, B. Boville, B. Briegleb, D. Williamson, and P. Rasch, 1996: Description of the NCAR Community Climate Model (CCM3). Tech. Rep. NCAR/TN5123 420+STR, 152 pp.

Kintisch, E., 2016: How a "Godzilla" El Niño shook up weather forecasts. Science, 352, 1501-1502, https://doi.org/10.1126/ science.352.6293.1501.
Koster, R. D., and Coauthors, 2010: Contribution of land surface initialization to subseasonal forecast skill: First results from a multi-model experiment. Geophys. Res. Lett., 37, L02402, https://doi.org/10.1029/2009GL041677.

Kug, J., F. Jin, and S. An, 2009: Two types of El Niño events: Cold tongue El Niño and warm pool El Niño. J. Climate, 22, 14991515, https://doi.org/10.1175/2008JCLI2624.1.

Kushnir, Y., R. Seager, M. Ting, N. Naik, and J. Nakamura, 2010: Mechanisms of tropical Atlantic SST influence on North American precipitation variability. J. Climate, 23, 5610-5628, https://doi.org/10.1175/2010JCLI3172.1.

Larson, S. M., and B. P. Kirtman, 2013: The Pacific meridional mode as a trigger for ENSO in a high-resolution coupled model. Geophys. Res. Lett., 40, 3189-3194, https://doi.org/ 10.1002/grl.50571.

— precursor and predictor in the North American multimodel ensemble. J. Climate, 27, 7018-7032, https://doi.org/10.1175/ JCLI-D-14-00055.1.

Lora, J. M., J. L. Mitchell, C. Risi, and A. E. Tripati, 2017: North Pacific atmospheric rivers and their influence on western North America at the Last Glacial Maximum. Geophys. Res. Lett., 44, 1051-1059, https://doi.org/10.1002/2016GL071541.

Lurie, J., 2015: The drought isn't just a California problem. Mother Jones, 21 August 2015, http://www.motherjones.com/ environment/2015/08/drought-isnt-just-california-problem.

McCabe, G. J., and M. D. Dettinger, 2002: Primary modes and predictability of year-to-year snowpack variations in the western United States from teleconnections with Pacific Ocean climate. J. Hydrometeor., 3, 13-25, https://doi.org/ 10.1175/1525-7541(2002)003<0013:PMAPOY >2.0.CO;2.

_, M. A. Palecki, and J. L. Betancourt, 2004: Pacific and Atlantic Ocean influences on multidecadal drought frequency in the United States. Proc. Natl. Acad. Sci. USA, 101, 4136-4141, https://doi.org/10.1073/pnas.0306738101.

Nagourney, A., 2015: California imposes first mandatory water restrictions to deal with drought. New York Times, 1 April 2015, https://www.nytimes.com/2015/04/02/us/california-imposesfirst-ever-water-restrictions-to-deal-with-drought.html.

Newman, M., and Coauthors, 2016: The Pacific decadal oscillation, revisited. J. Climate, 29, 4399-4427, https://doi.org/10.1175/ JCLI-D-15-0508.1.

Piechota, T. C., and J. A. Dracup, 1996: Drought and regional hydrologic variation in the United States: Associations with the El Niño-Southern Oscillation. Water Resour. Res., 32, 1359-1373, https://doi.org/10.1029/96WR00353.

Rayner, N. A., D. E. Parker, E. B. Horton, C. K. Folland, L. V. Alexander, D. P. Rowell, E. C. Kent, and A. Kaplan, 2003: Global analyses of sea surface temperature, sea ice, and night marine air temperature since the late nineteenth century. J. Geophys. Res., 108, 4407, https://doi.org/ 10.1029/2002JD002670.

Rice, D., 2015: California drought cost is 2.7 billion in 2015. USA Today, 19 August 2015, http://www.usatoday.com/story/ weather/2015/08/19/california-drought-cost-27-billion-2015/ $32007967 /$.

Sarachik, E., and M. A. Cane, 2010: The El Niño-Southern Oscillation Phenomenon. Cambridge University Press, 369 pp., https://doi.org/10.1017/CBO9780511817496.

Schubert, S. D., M. J. Suarez, P. J. Pegion, R. D. Koster, and J. T. Bacmeister, 2004: Causes of long-term drought in the U.S. Great Plains. J. Climate, 17, 485-503, https://doi.org/10.1175/ 1520-0442(2004)017<0485:COLDIT>2.0.CO;2. 
Seager, R., and M. Hoerling, 2014: Atmosphere and ocean origins of North American droughts. J. Climate, 27, 4581-4606, https://doi.org/10.1175/JCLI-D-13-00329.1.

—, Y. Kushnir, C. Herweijer, N. Naik, and J. Velez, 2005: Modeling of tropical forcing of persistent droughts and pluvials over western North America: 1856-2000. J. Climate, 18, 4065-4088, https://doi.org/10.1175/JCLI3522.1.

—, M. Hoerling, S. Schubert, H. Wang, B. Lyon, A. Kumar, J. Nakamura, and N. Henderson, 2015: Causes of the 2011-14 California drought. J. Climate, 28, 6997-7024, https://doi.org/ 10.1175/JCLI-D-14-00860.1.

Skinner, C. B., J. M. Lora, A. E. Payne, and C. J. Poulsen, 2020: Atmospheric river changes shaped mid-latitude hydroclimate since the mid-Holocene. Earth Planet. Sci. Lett., 541, 116293, https://doi.org/10.1016/j.epsl.2020.116293.

Stevenson, S., A. Timmermann, Y. Chikamoto, S. Langford, and P. DiNezio, 2015: Stochastically generated North American megadroughts. J. Climate, 28, 1865-1880, https://doi.org/10.1175/ JCLI-D-13-00689.1.

Trenberth, K. E., and C. J. Guillemot, 1996: Physical processes involved in the 1988 drought and 1993 floods in North
America. J. Climate, 9, 1288-1298, https://doi.org/10.1175/ 1520-0442(1996)009<1288:PPIITD>2.0.CO;2.

Vimont, D. J., 2005: The contribution of the interannual ENSO cycle to the spatial pattern of decadal ENSO-like variability. J. Climate, 18, 2080-2092, https://doi.org/10.1175/JCLI3365.1. von Storch, H. V., and F. W. Zwiers, 1999: Statistical Analysis in Climate Research. Cambridge University Press, Cambridge, $484 \mathrm{pp}$.

Williams, A. P., K. J. Anchukaitis, C. A. Woodhouse, D. M. Meko, B. I. Cook, K. Bolles, and E. R. Cook, 2020: Tree rings and observations suggest no stable cycles in Sierra Nevada coolseason precipitation. Water Resour. Res., 56, 2020WR028599, https://doi.org/10.1029/2020WR028599.

Wise, E. K., 2010: Spatiotemporal variability of the precipitation dipole transition zone in the western United States. Geophys. Res. Lett., 37, L07706, https://doi.org/10.1029/ 2009GL042193.

_ 2016: Five centuries of U.S. West Coast drought: Occurrence, spatial distribution, and associated atmospheric circulation patterns. Geophys. Res. Lett., 43, 4539-4546, https://doi.org/ 10.1002/2016GL068487. 